\title{
Metabolic health status and cardiovascular risk of different ABO blood group phenotypes
}

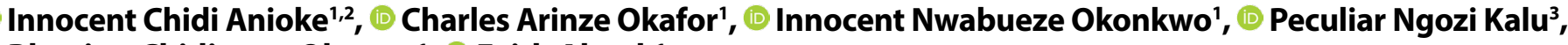 \\ Blessing Chidimma Okpagu', (1) Faith Akpah'
}

'Department of Medical Laboratory Sciences, Faculty of Health Sciences and Technology, College of Medicine, University of Nigeria Enugu Campus, Nigeria

${ }^{2}$ MSc. Public Health- Health Promotion, School of Health and Wellbeing, Faculty of Health and Social Science, Leeds Beckett University, Leeds, United Kingdom

${ }^{3}$ Department of Chemical Pathology, College of Medicine, Nnamdi Azikiwe University, Nnewi, Nigeria

\begin{abstract}
Objectives: $A B O$ blood group antigens could play a role in the pathogenesis of cardiovascular disease (CVD). This study examined the metabolic health status (MHS) and CVD risk of apparently healthy individuals from across the ABO blood group system.

Methods: Demographic details as well as anthropometric and biochemical data were collected in a cross-sectional survey from 120 participants of different ABO groups (range: 18-70 years). Height, weight, and waist circumference were measured using standard procedures. Body mass index was calculated as weight divided by height squared (kg/ $\mathrm{m}^{2}$ ). A blood sample of approximately $5 \mathrm{~mL}$ was collected after an overnight fast. Fasting blood glucose was estimated using a glucometer. The blood group was determined using a monoclonal ABO blood grouping reagent. Direct enzymatic methods and a commercial kit were used to measure the level of total cholesterol (TC), triglycerides, and highdensity lipoprotein. Low-density lipoprotein (LDL) and very low-density lipoproteins were estimated using the Friedewald equation. Metabolically healthy $(\mathrm{MH})$ and metabolically unhealthy $(\mathrm{MUH})$ individuals were identified based on the presence of metabolic syndrome using the Joint Interim Statement criteria. CVD risk was determined using the Systematic Coronary Risk Evaluation chart.

Results: Females showed significant differences in TC across the ABO system: The O group (mean \pm SD: $4.85 \pm 0.77$ $\mathrm{mmol} / \mathrm{L}$ ) demonstrated a significantly higher TC level compared with the A group (mean $\pm \mathrm{SD}: 4.22 \pm 0.72 \mathrm{mmol} / \mathrm{L}$; $\mathrm{p}=0.015)$. The $L D L$ in females was also significantly higher in the $O$ group samples (mean $\pm S D: 3.06 \pm 0.75 \mathrm{mmol} / \mathrm{L}$ ) compared with the A samples (mean $\pm S D: 2.53 \pm 0.62 \mathrm{mmol} / \mathrm{L} ; \mathrm{p}=0.042$ ). There was no significant difference between the $\mathrm{MUH}$ and $\mathrm{MH}$ groups based on ABO blood phenotype ( $p>0.05$ ). The CVD risk among those with the O phenotype $(51.7 \%)$ was significantly higher than in the non-O blood groups among male subjects $\left(\chi^{2}=6.213 ; p=0.045\right)$.

Conclusion: MHS was not associated with the $A B O$ system, but there is a possibility that male members of blood group $\mathrm{O}$ are more susceptible to CVD than men with non-O phenotypes.

Keywords: ABO blood group system, cardiovascular disease risk, metabolically (un)healthy, metabolic health status, metabolic syndrome
\end{abstract}

C inically, certain cardio-metabolic risk determinants often occur in a cluster of components of obesity, dyslipidemia, hypertension, and hyperglycemia [1]. This formed the basis of the definition of metabolic syndrome (MetSyn). Various sets of criteria for the diagnosis of MetSyn have been proposed using a different number and combination of these compo-

Address for correspondence: Innocent Chidi Anioke, MD. Department of Medical Laboratory Sciences, Faculty of Health Sciences and Technology, College of Medicine, University of Nigeria Enugu Campus, Nigeria

Phone: +2348066752664 E-mail: innocent.anioke@unn.edu.ng ORCID: 0000-0001-7600-4823

Submitted Date: March 19, 2019 Accepted Date: April 17, 2019 Available Online Date: June 13, 2019

${ }^{\circ}$ Copyright 2019 by International Journal of Medical Biochemistry - Available online at www.internationalbiochemistry.com OPEN ACCESS This work is licensed under a Creative Commons Attribution-NonCommercial 4.0 International License. 
nents $[2,3]$. As defined by the Joint Interim Statement (JIS), the MetSyn components are an excessive waist circumference, high triglyceride (TG) level, low high-density lipoprotein (HDL) cholesterol level, elevated blood pressure, and a high fasting plasma glucose (FPG) level. The presence of at least 3 of the 5 components meets the definition of MetSyn (termed metabolically unhealthy [MUH] in this study) [2]. Regardless of which definition is adopted, prior evidence underpins the understanding that MetSyn is significantly linked with a greater risk for cardiovascular disease (CVD) and type 2 diabetes, especially in men $[4,5]$. Notably, a 2-fold increase in CVD has been reported [6].

The $\mathrm{ABO}$ blood group is considered an overarching genetic determinant of CVD risk [7]. Advances in technology, biochemistry, and genetics have clarified to a plausible extent the association of blood group types - especially the human blood group antigens, $\mathrm{A}, \mathrm{B}$, and $\mathrm{H}(\mathrm{O})$ - and their relationship to risk for disease [8]. Extensive, evidence-based, scientific validation has substantiated the association between $\mathrm{ABO}$ blood groups and diseases such as cancer, infection, coagulation disorders, diabetes, and CVD $[8,9]$. Thus, the study of ABO blood group phenotypes remains a fascinating field, given its role in the pathogenesis of different diseases, particularly CVD $[7,9]$. The influence of $A B O$ blood groups on the cardio-metabolic health status of an individual is multifaceted, because $\mathrm{MUH}$ status and the risk of CVD is a multi-factorial condition that is not controlled by just a single blood group antigen [8]. This suggests the involvement of a complex etiological interaction of genetic and socio-environmental risk factors in the development of CVD [10].

Understanding the distribution of metabolic risk factors in different $A B O$ blood phenotypes in a certain population is important because the distribution of blood group antigens differs across ethnicity and race [11]. There is increasing evidence reinforcing an association between the $A B O$ blood group system and the risk of developing CVD, which may provide for tailored management of some disease conditions.

In an effort to understand the relationship between $A B O$ blood group phenotypes and evidence underpinning an association between the $\mathrm{ABO}$ blood group system and the risk of developing CVD, several epidemiological studies have characterized lipid profile distributions in individuals with or without metabolic disease across the ABO blood group system [7, 10, 1214]. However, research examining the metabolic health status of individuals according to $\mathrm{ABO}$ blood group, which may be an important genetic determinant for CVD processes, remains limited. Understanding metabolic health status (MHS) in the context of the $A B O$ system may pave the way for improved CVD management, or better still, it could potentially serve as a predictive index of CVD in society at large. The goal of the present study was to analyze the MHS and CVD risk of apparently healthy participants from all of the $A B O$ blood phenotypes with the following specifics objectives: (1) characterize and compare the level of different components of MetSyn across $A B O$ subtypes, (2) estimate the prevalence of MUH subjects across $A B O$ subtypes by gender, and (3) determine the level of cardiovascular risk associated with each ABO subtype.

\section{Materials and Methods}

\section{Study design and subject characteristics}

A group of 120 apparently healthy individuals, comprised of males $(n=60)$ and females $(n=60)$ between the ages of 18 and 70 years, were recruited for a cross-sectional study in the city of Enugu, in southeastern Nigeria. The participants were sorted according to their ABO blood group type. MHS was determined using the Joint Interim Statement criteria on harmonizing a diagnosis of MetSyn, which requires the presence of 3 of 5 components for diagnosis:

1. Excessive waist circumference (WC) of $\geq 94 \mathrm{~cm}$ for men and $\geq 80 \mathrm{~cm}$ for females in sub-Saharan Africa

2. High TG level of $\geq 150 \mathrm{mg} / \mathrm{dL}$ (1.7 mmol/L) or use of lipidlowering drugs

3. Low HDL level of $<40 \mathrm{mg} / \mathrm{dL}$ ( $1.04 \mathrm{mmol} / \mathrm{L})$ for men and $<50 \mathrm{mg} / \mathrm{dL}$ ( $1.3 \mathrm{mmol} / \mathrm{L})$ for women

4. Elevated blood pressure (BP) of systolic BP (SBP) $\geq 130$ $\mathrm{mmHg}$ and/or diastolic BP (DBP) $\geq 85 \mathrm{mmHg}$, or use of or anti-hypertensive drugs.

5. High FPG level of $\geq 100 \mathrm{mg} / \mathrm{dL}$ (5.6 mmol/L) or medication for diabetes (insulin or oral anti-diabetic) [2].

Participants who did not meet at least 3 of the 5 criteria were considered metabolically healthy $(\mathrm{MH})$, i.e., without MetSyn. This study was approved by the University of Nigeria Teaching Hospital Health Research Ethics Committee, Ituku-Ozalla Enugu (NHREC/05/01/2008B-FWA00002458-1RB00002323). Participants who willingly consented to participate after due explanation of the purpose and nature of the study were included in the study.

\section{Social demographic details}

All of the participants completed a well-structured, self-administered questionnaire that included social demographic variables, such as gender, age, alcohol use, smoking status, and physical (in)activity.

\section{Anthropometric measurements}

Body weight was measured in kilograms $(\mathrm{kg})$. Patients were weighed after removing heavy clothing, such as shoes and belts, using a digital Soehnle electronic scale (Leifheit AS, Nassau/Lahn, Germany). Height was measured using a stadiometer, with the participant standing erect in bare feet with the head in the Frankfurt plane. Body mass index (BMI) was calculated as body weight divided by height squared $\left(\mathrm{kg} / \mathrm{m}^{2}\right)$. WC was measured $(\mathrm{cm})$ at the level of the iliac crest using a measuring tape while the participants exhaled. The blood 
pressure index was measured twice in a sitting position after 5 minutes of rest with a mercury sphygmomanometer according to standard protocol. The mean result was recorded in $\mathrm{mmHg}$ for each patient. The same measuring instruments were employed in the data collection of all patients to ensure reliability and validity of results.

\section{Cardiovascular disease risk assessment}

Assessment of CVD risk was performed using the Systematic Coronary Risk Evaluation (SCORE) chart [15], which has been recommended in European guidelines on CVD prevention in clinical practice based on large, representative, European cohort datasets. The SCORE chart estimates the 10-year risk of fatal CVD in high/low CVD risk populations based on certain risk components, such as age, gender, smoking, SBP, and total cholesterol (TC). It was designed to facilitate risk estimation in apparently healthy individuals with no documented CVD [16].

\section{Biochemical laboratory assessment}

A fasting blood sample of about $5 \mathrm{~mL}$ was collected from each participant using a sterile syringe. The FPG value was estimated using a point-of-care glucose testing device (glucometer). About $1.0 \mathrm{~mL}$ of the blood sample from each participant was added to an ethylenediaminetetraacetic acid sample container, then sealed and labeled for $A B O$ grouping. The remaining $4 \mathrm{~mL}$ of blood was centrifuged after clotting and retraction to separate the serum for the estimation of the lipid profile. The serum samples were preserved in a refrigerator for a period of 24 to 48 hours while the lipid profile tests were conducted.

The blood group was determined using a monoclonal $A B O$ blood grouping reagent (Clas Technology Ltd., Dungannon,
UK). The quantitative determination of the lipid profile parameters of TC, TG, and HDL was performed using direct enzymatic assay methods and a commercial kit (Randox Laboratories Ltd., Crumlin, UK). The low-density lipoprotein (LDL) and very low-density lipoprotein (VLDL) values were estimated using the Friedewald equation:

$\mathrm{LDL}-\mathrm{C}(\mathrm{mmol} / \mathrm{L})=\mathrm{TC}-[\mathrm{HDL}-\mathrm{C}+\mathrm{TG} / 2.2]$; where VLDL=TG/2.2.

\section{Data analysis}

The data were analyzed using IBM SPSS Statistics for Windows, Version 20.0 (IBM Corp., Armonk, NY, USA). Descriptive statistics, one-way analysis of variance with the Tukey post hoc multiple comparison test, and a chi-square test were used, as appropriate, to compare and estimate the metabolic health status (i.e., proportion of $\mathrm{MH}$ and $\mathrm{MUH}$ ) and cardiovascular risk according to the $\mathrm{ABO}$ blood system group. Only the 3 predominant $A B O$ blood group subtypes within the study population: $O, A$, and $B$, in that order, were used for analysis [13]. The $A B$ blood subtype did not satisfy the statistical assumption of adequate cell size for analysis and it was excluded from the analysis. Significance was set at $\mathrm{p}<0.05$.

\section{Results}

Table 1 demonstrates that there was no significant difference across the ABO system in the components of MetSyn in the studied population $(p>0.05)$.

The proportion of study participants classified as MUH and those who were grouped as MH was not significantly different across $A B O$ subtypes ( $p>0.05$ ) (Table 2 ). This suggests that no $A B O$ blood subtype is more or less likely to be metabolically healthy or unhealthy. The level of CVD risk for the A (19.4\%) and $B(27.8 \%)$ groups was significantly lower than that of the

Table 1. Components of metabolic syndrome according to ABO blood group in the study group (n=119)

\begin{tabular}{|c|c|c|c|c|}
\hline Parameters & $\begin{array}{l}\text { A } \\
42(35.3 \%)\end{array}$ & $\begin{array}{l}\text { B } \\
20(16.8 \%)\end{array}$ & $\begin{array}{l}0 \\
57(47.9 \%)\end{array}$ & $\mathbf{P}$ \\
\hline Age (years) & $34.07 \pm 11.23$ & $41.40 \pm 16.10$ & $38.09 \pm 11.88$ & 0.078 \\
\hline LDL (mmol/L) & $2.62 \pm 0.66$ & $2.72 \pm 0.68$ & $2.71 \pm 0.72$ & 0.782 \\
\hline TG (mmol/L) & $0.99 \pm 0.43$ & $0.90 \pm 0.33$ & $1.02 \pm 0.44$ & 0.491 \\
\hline SBP (mmHg) & $118.31 \pm 16.90$ & $116.00 \pm 15.28$ & $116.33 \pm 23.61$ & 0.867 \\
\hline $\mathrm{DBP}(\mathrm{mmHg})$ & $78.83 \pm 10.92$ & $74.50 \pm 10.80$ & $78.42 \pm 11.32$ & 0.320 \\
\hline $\mathrm{FPG}(\mathrm{mg} / \mathrm{dL})$ & $88.95 \pm 15.11$ & $88.70 \pm 17.32$ & $92.00 \pm 0.00$ & 0.505 \\
\hline BMI $\left(\mathrm{kg} / \mathrm{m}^{2}\right)$ & $27.84 \pm 9.68$ & $28.28 \pm 7.86$ & $28.05 \pm 00.00$ & 0.985 \\
\hline WC $(\mathrm{cm})$ & $92.29 \pm 10.44$ & $87.81 \pm 7.99$ & $92.33 \pm 0.00$ & 0.163 \\
\hline
\end{tabular}

Mean \pm SD; Statistical non-significance; $P>0.05$ with Turkey Post-Hoc tests used for multiple comparisons analysis between ABO groups for each parameter. BMI: Body mass index; DBP: Diastolic blood pressure; FPG: Fasting plasma glucose; HDL: High-density lipoprotein; LDL: Low-density lipoprotein; SBP: Systolic blood pressure; TC: Total cholesterol; TG: Total triglyceride; VLDL: Very low-density lipoprotein; WC: Waist circumference. 


\begin{tabular}{|c|c|c|c|}
\hline Blood group & $\begin{array}{l}\text { Metabolically } \\
\text { healthy, n (\%) }\end{array}$ & $\begin{array}{l}\text { Metabolically } \\
\text { unhealthy, n (\%) }\end{array}$ & $\begin{array}{l}\chi^{2} \text { value } \\
\text { P value }\end{array}$ \\
\hline A & $36(35.0)$ & $6(37.5)$ & \\
\hline B & $17(16.5)$ & $3(18.8)$ & $\chi^{2}=0.133$ \\
\hline 0 & $50(48.5)$ & $7(43.8)$ & $P=0.935$ \\
\hline Total & $103(100)$ & $16(100)$ & \\
\hline Blood group & CVD-at risk & $\begin{array}{l}\text { CVD-not } \\
\text { at risk }\end{array}$ & $\begin{array}{l}\chi^{2} \text { value } \\
P \text { value }\end{array}$ \\
\hline$A$ & $7(19.4)$ & $35(42.2)$ & \\
\hline B & $10(27.8)$ & $10(12.0)$ & $\chi^{2}=7.627$ \\
\hline $\mathrm{O}$ & $20(52.8)$ & $37(45.8)$ & $\mathrm{P}=0.022^{*}$ \\
\hline Total & $36(100 \%)$ & $83(100 \%)$ & \\
\hline
\end{tabular}

*Statistical significance: $p<0.05$; CVD: Cardiovascular disease.

O group (52.8\%); the members of the $\mathrm{O}$ blood subtype group were more likely to be at risk of $C V D\left(\chi^{2}=7.627 ; p=0.022\right)$.

Table 3 illustrates that significant differences in the TC and $\mathrm{LDL}(\mathrm{mmol} / \mathrm{L})$ were observed across the ABO system among females. The $O$ blood group had a significantly higher level of TC (mean $\pm S D: 4.85 \pm 0.77 \mathrm{mmol} / \mathrm{L}$ ) compared with the A group (mean $\pm S D: 4.22 \pm 0.72 \mathrm{mmol} / \mathrm{L} ; \mathrm{p}=0.015)$. The $\mathrm{LDL}$ in blood group O (mean \pm SD: $3.06 \pm 0.75 \mathrm{mmol} / \mathrm{L}$ ) was significantly higher compared with the A group (mean $\pm S D: 2.53 \pm 0.62 \mathrm{mmol} / \mathrm{L}$; $p=0.042$ ). However, none of the components of MetSyn revealed a significant difference between $\mathrm{ABO}$ blood groups.

In Table 4 it can be seen that there was no significant difference among female patients in the proportion of those with MUH status compared with the MH participants across each
Table 4. Proportion of females classified as metabolically healthy and unhealthy and the CVD risk across $A B O$ blood groups

\begin{tabular}{llll}
\hline Blood group & $\begin{array}{l}\text { Metabolically } \\
\text { healthy, } \mathbf{n}(\%)\end{array}$ & $\begin{array}{l}\text { Metabolically } \\
\text { unhealthy, } \mathbf{n}(\%)\end{array}$ & $\begin{array}{l}\chi^{2} \text { value } \\
\text { P value }\end{array}$ \\
\hline A & $16(35.6)$ & $5(35.7)$ & \\
B & $7(15.6)$ & $2(14.3)$ & $\chi^{2}=0.014$ \\
O & $22(48.9)$ & $7(50.0)$ & $P=0.993$ \\
Total & $45(100)$ & $14(100)$ & \\
Blood group & CVD-at risk & CVD-not & $\chi^{2}$ value \\
& & at risk & value \\
\hline A & $1(14.3)$ & $20(38.5)$ & \\
B & $2(28.6)$ & $7(13.5)$ & $\chi^{2}=2.040$ \\
O & $4(57.1)$ & $25(48.1)$ & $P=0.361$ \\
Total & $7(100 \%)$ & $52(100 \%)$ & \\
\hline
\end{tabular}

CVD: Cardiovascular disease.

$A B O$ subtype ( $p>0.05)$, suggesting that no $A B O$ blood subtype was more or less likely than another to be metabolically healthy or unhealthy. Furthermore, the CVD risk did not differ significantly across the $A B O$ blood group system among females $\left(\chi^{2}=2.040 ; p=0.361\right)$. No $A B O$ blood group was more or less likely at risk of CVD among the female subjects studied.

Table 5 demonstrates that there was no observed significant difference in any of the MetSyn components in the male subjects across the $A B O$ subgroups ( $p>0.05$ ).

In Table 6 it can be seen that the proportion of male subjects in each $A B O$ group with $M U H$ status was not significantly different from that of the MH participants $\left(\chi^{2}=2.230 ; p=0.328\right)$. This indicates that no blood group was more or less metabolically

Table 3. Components of metabolic syndrome according to ABO blood group in the female subjects $(n=59,49.6 \%)$

\begin{tabular}{|c|c|c|c|c|}
\hline Parameters & $\begin{array}{l}A \\
(n=21)\end{array}$ & $\begin{array}{l}\text { B } \\
(n=9)\end{array}$ & $\begin{array}{l}0 \\
(n=29)\end{array}$ & $\mathbf{P}$ \\
\hline Age (years) & $27.10 \pm 6.63$ & $36.44 \pm 16.67$ & $33.52 \pm 12.64$ & 0.073 \\
\hline TG (mmol/L) & $0.96 \pm 0.47$ & $0.93 \pm 0.32$ & $1.02 \pm 0.46$ & 0.834 \\
\hline $\mathrm{TC}$ (mmol/L) & $4.22 \pm 0.72^{\mathrm{a}}$ & $4.34 \pm 0.82^{b}$ & $4.85 \pm 0.77^{c}$ & $0.015^{*}$ \\
\hline SBP $(\mathrm{mmHg})$ & $119.43 \pm 16.78$ & $116.22 \pm 13.53$ & $117.79 \pm 28.47$ & 0.935 \\
\hline $\mathrm{DBP}(\mathrm{mmHg})$ & $79.29 \pm 10.09$ & $75.22 \pm 14.21$ & $79.00 \pm 11.22$ & 0.636 \\
\hline FPG (mg/dL) & $90.19 \pm 19.41$ & $81.67 \pm 15.93$ & $93.86 \pm 16.91$ & 0.203 \\
\hline $\mathrm{BMI}\left(\mathrm{kg} / \mathrm{m}^{2}\right)$ & $33.19 \pm 11.37$ & $34.33 \pm 8.32$ & $33.44 \pm 11.11$ & 0.965 \\
\hline WC $(\mathrm{cm})$ & $98.96 \pm 8.59$ & $90.59 \pm 9.33$ & $98.10 \pm 9.37$ & 0.063 \\
\hline
\end{tabular}

Mean $\pm S D ; *$ Statistical significance: $p<0.05$ with Tukey post hoc test used for multiple comparisons between $A B O$ groups: ${ }^{a}=A$ vs $O$ showed significant decrease; ${ }^{c}=0$ vs $A$ showed significant increase; ${ }^{b}=\mathrm{B}$ vs A and O, respectively, showed no significant difference; BMI: Body mass index; DBP: Diastolic blood pressure; FPG: Fasting plasma glucose; HDL: High-density lipoprotein; LDL: Low-density lipoprotein; SBP: Systolic blood pressure; TC: Total cholesterol; TG: Total triglyceride; VLDL: Very low-density lipoprotein; WC: Waist circumference. 
Table 5. Components of metabolic syndrome according to $A B O$ blood group in the male subjects $(n=60,50.4 \%)$

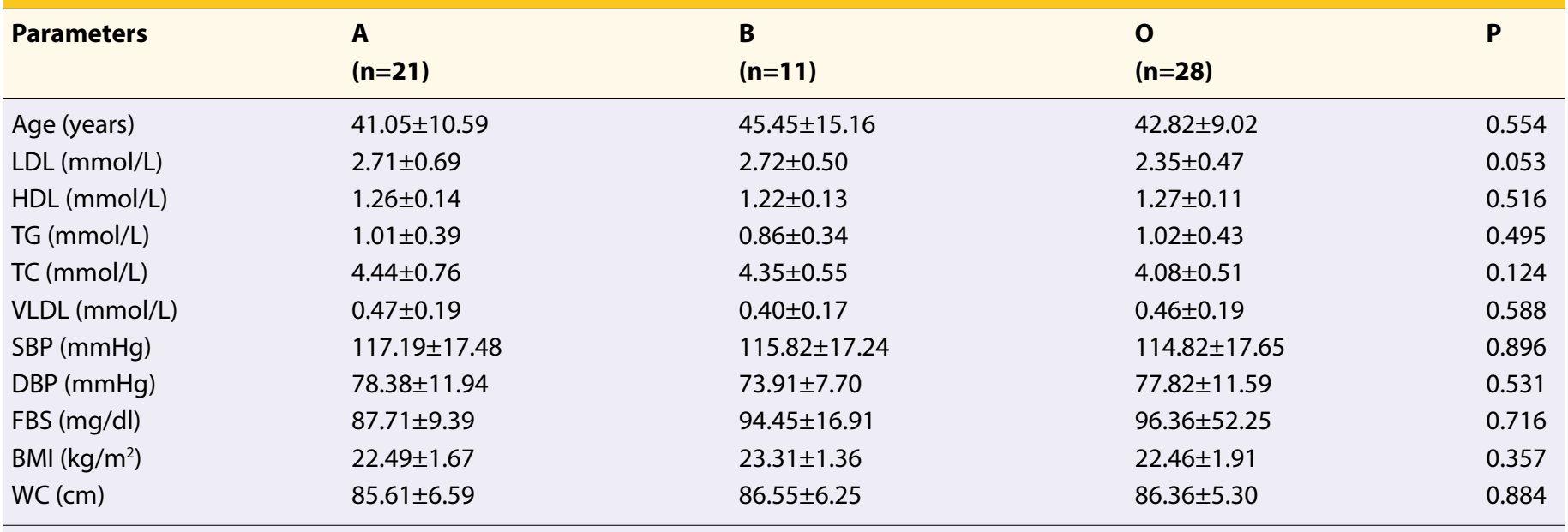

Mean \pm SD; Statistical non-significance; $P>0.05$ with Turkey Post-Hoc tests used for multiple comparisons analysis between $A B O$ groups for each parameter; $B$ MI: Body mass index; DBP: Diastolic blood pressure; FPG: Fasting plasma glucose; HDL: High-density lipoprotein; LDL: Low-density lipoprotein; SBP: Systolic blood pressure; TC: Total cholesterol; TG: Total triglyceride; VLDL: Very low-density lipoprotein; WC: Waist circumference.

\begin{tabular}{|c|c|c|c|}
\hline Blood group & $\begin{array}{l}\text { Metabolically } \\
\text { healthy, n (\%) }\end{array}$ & $\begin{array}{l}\text { Metabolically } \\
\text { unhealthy, n (\%) }\end{array}$ & $\begin{array}{l}\chi^{2} \text { value } \\
\text { P value }\end{array}$ \\
\hline A & $20(34.5)$ & $1(50.0)$ & \\
\hline B & $10(17.2)$ & $1(50.0)$ & $\chi^{2}=2.230$ \\
\hline $\mathrm{O}$ & $28(48.3)$ & $0(0.0)$ & $P=0.328$ \\
\hline Total & $58(100)$ & $2(100)$ & \\
\hline Blood group & CVD-at risk & $\begin{array}{l}\text { CVD-not } \\
\text { at risk }\end{array}$ & $\begin{array}{l}\chi^{2} \text { value } \\
\text { P value }\end{array}$ \\
\hline$A$ & $6(20.7 \%)$ & 15 (48.4\%) & \\
\hline$B$ & $8(27.6 \%)$ & $3(9.7 \%)$ & $\chi^{2}=6.213$ \\
\hline $\mathrm{O}$ & 15 (51.7\%) & $13(41.9 \%)$ & $P=0.045^{*}$ \\
\hline Total & $29(100 \%)$ & 31 (100\%) & \\
\hline
\end{tabular}

*Statistical significance: $p<0.05$.

unhealthy or healthy among the male subjects. However, the level of CVD risk among blood group O (51.7\%) was significantly greater $\left(\chi^{2}=6.213 ; p=0.045\right)$ compared with that of the non-O blood groups. Males in the $O$ subtype group had the highest risk for CVD in the study population.

\section{Discussion}

This examination of the components of MetSyn, which are cardio-metabolic risk determinants (age, lipid profile parameters, FPG, BP, BMI, and WC), between blood subtypes revealed no significant difference across the $\mathrm{ABO}$ blood group system in the study group. The results were largely similar across the $A B O$ groups among the male subjects. However, there were significant differences observed in the TC and LDL values according to the $A B O$ system group classification among the female subjects. The women in the blood group $\mathrm{O}$ category demonstrated a higher level of TC and LDL compared with those in blood group A. Our finding in the general populationparticularly among the males agreed with the documented evidence presented by Ghazaee et al. [17] and Farah et al., [18] which reported no significant difference in the lipid profile distribution among the different $\mathrm{ABO}$ blood groups. Some researchers $[10,13,19-21]$ have reported a significant difference in lipid profile distribution between different $A B O$ blood group antigens. For instance, a study of the Iranian population showed that hyperlipidemia was more frequent in other ABO groups than in blood group B [21], whereas other authors found that $\mathrm{HDL}$ and $\mathrm{LDL}$ had significantly different mean values across ABO blood groups [10]. Recently, Ureme et al. [13] revealed that blood group $\mathrm{O}$ might have a higher propensity for dyslipidemia, given that the highest level of LDL and the lowest level of HDL were reported in this blood group.

The results of this study indicated that there was no significant difference in the number of those with MUH or MH status according to $A B O$ subtype. This was true for both female and male subjects. This implies that no blood group in the studied sample was more or less metabolically unhealthy than another. Many studies have revealed possible associations between various diseases, especially cardio-metabolic diseases, and the $\mathrm{ABO}$ blood groups, but the reasons for such an association remain controversial $[8,10,22,23]$.

The present study revealed that the level of CVD risk for blood groups A and B was significantly lower compared with that of the $O$ group. The level of CVD risk among females did not differ significantly between groups; however, among male subjects, the level of CVD risk in members of blood group $\mathrm{O}$ was significantly increased compared to non-O blood groups. This finding is consistent with prior studies reporting evidence of an 
association between ABO blood subtypes and risk of CVD [10, $13,17,18,21,23-27]$. However, there is inconsistency in these prior findings as to which $\mathrm{ABO}$ blood subtype is at greater risk of CVD. Some studies [10, 13, 21] have reported that individuals with blood group $\mathrm{O}$ were at highest risk for CVD, but this was not replicated in other studies [17, 18, 23-27].

Our study results are similar to those of Anvari et al. [21], which indicated that the prevalence of coronary heart diseases was markedly higher in blood group $\mathrm{O}$ compared with the other $\mathrm{ABO}$ blood groups. Another study that was consistent with our findings was conducted among the Bengali population of eastern India. It found that a low HDL was the major CVD risk factor in healthy $O$ blood group subjects [10]. Nafakhi et al. [27] suggested that there was no significant association between $A B O$ blood group and CVD. Similarly, Jukic et al. [28] found there was no statistically significant difference between the blood groups in relation to their association with acute myocardial infarction. Anstee [29] reported that an association between blood group and CVD risk may only exist with non-O blood subtypes. Contrary to our findings, it was reported in a study performed in Senegal that the incidence of ischemic CVD in men was significantly higher in blood group A [23]. In the context of CVD in general, the level of risk of CVD associated with different $A B O$ subtypes observed in our study, especially in blood group $\mathrm{O}$, may not, in fact, differ from the study done in Senegal. The authors evaluated the prevalence of ischemic and non-ischemic CVD in patients of different $A B O$ blood groups and reported that the diagnosis of ischemic disease (e.g., stroke, coronary artery disease, myocardial infarction) was $61.2 \%$ higher in blood group A compared with the other blood groups. The diagnosis of non-ischemic disease (e.g., heart failure, valvular disease, cerebral hemorrhage) was $73.6 \%$ higher in blood group 0 compared with the other blood groups [23]. Although our study did not stratify the type of CVD, both studies seem to indicate that individuals in sub-Saharan Africa with blood type $\mathrm{O}$ might be at increased risk of developing some form of CVD.

The inconsistent results in the literature may be attributable to ethnic variation in $A B O$ antigens, varying sample size in different studies, and other unadjusted or unaccounted confounders for CVD. According to Liumbruno and Zranchini [22], the contrasting results on this issue suggest that the association between $A B O$ blood group and risk of CVD is still unclear and deserves further investigation. A population-based prospective study is needed in Nigeria. This, in particular, could validate a possible etiological link between $A B O$ blood group antigens and the risk of CVD, which could potentially serve as a predictive index for CVD in this population.

\section{Study limitations}

This study has some limitations. A causal link between $A B O$ blood group and CVD risk cannot be ascertained as the study was a cross-sectional investigation and could only investigate an association. The AB blood group did not have an adequate representative sample in this study, likely because it is the rarest of the $A B O$ blood group subtypes in the studied population [13]. Only blood groups that satisfied the statistical assumption of adequate cell size for analysis were included: Our study examined the $A, B$, and $O$ blood groups. Further study should be conducted with a well-represented sample for each $A B O$ blood group. Additionally, a convenience sampling technique was used; therefore, generalization of results should be undertaken with caution. Covariates or confounders, such as smoking status, alcohol use, family history, physical inactivity, consumption of fruit and vegetables, and the use of some drugs, were not accounted for in the present study given that these data were generated from a self-administered questionnaire that produced a response favoring the positive/good replies, suggesting that the self-report process might have introduced social desirability bias.

The current study did not account for any underlying disorders, such as renal or liver disease, diabetes mellitus, a very high TG level of above $4.52 \mathrm{mmol} / \mathrm{L}(400 \mathrm{mg} / \mathrm{dL})$, a very low level of triglyceride of below $1.13 \mathrm{mmol} / \mathrm{L}(100.10 \mathrm{mg} / \mathrm{dL})$, or type III hyperlipidemia in the subjects recruited, which is capable of impacting the accuracy of Friedewald's formula used to estimate LDL [30]. LDL cholesterol overestimation is possible, as the formula does not differentiate between cholesterol derived from LDL and lipoprotein(a) in the face of elevated levels of lipoprotein(a) [30]. The Friedewald formula was applied in the current study because it had better agreement with a direct method for LDL measurement in healthy subjects [31] and appeared to have the best overall performance for LDL calculation when compared with other formulae in patients with dyslipidemias and co-morbidities [32].

\section{Conclusion}

The proportion of those classified as MUH in each $\mathrm{ABO}$ blood group was not significantly different from those who were considered $\mathrm{MH}$. Male subjects of blood group $\mathrm{O}$ were associated with an increased risk for CVD, though the result may not have been independent of conventional cardio-metabolic risk factors. Consideration of blood group antigens alongside other convectional cardio-metabolic risk factors may offer helpful insights into understanding an individual's risk for developing CVD in the future.

\section{Conflict of interest: None declared.}

Ethics Committee Approval: This study was approved by the University of Nigeria Teaching Hospital Health Research Ethics Committee, Ituku-Ozalla Enugu (NHREC/05/01/2008BFWA00002458-1RB00002323).

Financial Disclosure: No funding was provided for the project.

Peer-review: Externally peer-reviewed.

Authorship contributions: Concept - I.C.A.; Design - P.N.K.; Supervision - I.C.A., C.A.O., I.N.O.; Data collection \&/or processing F.A., B.C.O.; Analysis and/or interpretation - I.C.A.; Literature search 
- C.A.O.; Writing - I.C.A., P.N.K.; Critical review - I.C.A., C.A.O., I.N.O., P.N.K., B.C.O., F.A.

\section{References}

1. Cooper-DeHoff RM, Pepine CJ. Metabolic syndrome and cardiovascular disease: challenges and opportunities. Clin Cardiol 2007;30:593-7. [CrossRef]

2. Alberti KG, Eckel RH, Grundy SM, Zimmet PZ, Cleeman I, Donato KA, et al. Harmonizing the metabolic syndrome: a joint interim statement of the InternationalDiabetes Federation Task Force on Epidemiology and Prevention; National Heart, Lung, and Blood Institute; American Heart Association; World Heart Federation; InternationalAtherosclerosis Society; and International Association for the Study of Obesity. Circulation 2009;120:1640-5. [CrossRef]

3. Boumaiza I, Omezzine A, Romdhane M, Rejeb J, Rebhi L, Bouacida $L$, et al. Metabolic Syndrome according to Three Definitions in Hammam-Sousse Sahloul Heart Study: A City Based Tunisian Study. Advances in Epidemiology 2014:1-10. [CrossRef]

4. Lakka HM, Laaksonen DE, Lakka TA, Niskanen LK, Kumpusalo $\mathrm{E}$, Tuomilehto J, et al. The metabolic syndrome and total and cardiovascular disease mortality in middle-aged men. JAMA 2002;288:2709-16. [CrossRef]

5. Wilson PW, D'Agostino RB, Parise H, Sullivan L, Meigs JB. Metabolic syndrome as a precursor of cardiovascular disease and type 2 diabetes mellitus. Circulation 2005; 112:3066-72.

6. Mottillo S, Filion KB, Genest J, Joseph L, Pilote L, Poirier P, et al. The metabolic syndrome and cardiovascular risk a systematic review and meta-analysis. J Am Coll Cardiol 2010;56:1113-32.

7. Zhang Y, Li S, Zhu CG, Guo YL, Wu NQ, Xu RX, et al. Risk Factors, Coronary Severity, Outcome and ABO Blood Group: A Large Chinese Han Cohort Study. Medicine (Baltimore) 2015 Oct;94:e1708. [CrossRef]

8. Ewald DR, Sumner SC. Blood type biochemistry and human disease. Wiley Interdiscip Rev Syst Biol Med 2016;8:517-35.

9. Zhang H, Mooney CJ, Reilly MP. ABO Blood Groups and Cardiovascular Diseases. Int J Vasc Med 2012;2012:641917. [CrossRef]

10. Biswas S, Ghoshal PK, Halder B, Mandal N. Distribution of ABO blood group and major cardiovascular risk factors with coronary heart disease. Biomed Res Int 2013;2013:782941. [CrossRef]

11. Iyiola OA, Igunnugbemi OO, Anifowoshe AT, Raheem UA. Gene frequencies of $\mathrm{ABO}$ and $\mathrm{Rh}(\mathrm{D})$ blood group alleles in Illorin, North-central Nigeria. World Journal of Biological Research 2011;4:6-14.

12. Bartimaeus ES, Waribo HA. Relationship between ABO Blood Groups and Lipid Profile Level in Healthy Adult Residents in Port Harcourt Metropolis, Nigeria. J Appl Sci Environ Manage 2017;21:1003-11. [CrossRef]

13. Ureme SO, Anioke IC, Igboerika C. Lipid Profiles in Different $A B O$ Blood groups in Owerri Metropolis, South East Nigeria: $A$ preliminary Study. Asian Journal of Research in Biochemistry 2018;2:1-7.

14. Iheanocho KME, Offiah SAU, Udo M, Ugonabu MC, Onukagu IV, Onwubiko D, et al. Evaluation of Lipid Profile of Different
ABO Blood Groups. International Journal of Research Studies in Medical and Health Science 2018;3:13-4.

15. Conroy RM, Pyörälä K, Fitzgerald AP, Sans S, Menotti A, De Backer $G$, et al. Estimation of ten-year risk of fatal cardiovascular disease in Europe: the SCORE project. Eur Heart J 2003;24:987-1003. [CrossRef]

16. Authors/Task Force Members:, Catapano AL, Graham I, De Backer G, Wiklund O, Chapman MJ, Drexel H, et al. 2016 ESC/ EAS Guidelines for the Management of Dyslipidaemias: The Task Force for the Management of Dyslipidaemias of the European Society of Cardiology (ESC) and European Atherosclerosis Society (EAS) Developed with the special contribution of the European Assocciation for Cardiovascular Prevention \& Rehabilitation (EACPR). Atherosclerosis 2016;253:281-344.

17. Ghazaee SP, Backshandeh $H$, Mehrzad N, Khaleghparast S. $\mathrm{ABO} / \mathrm{Rh}$ blood groups distribution and serum lipid profile: Is there any association? Journal of Society for development in new net environment in B\&H 2014;8:194-8.

18. Farah A, Zaini R, Kufia R. Relationship of blood group with risk factors for cardiovascular diseases. Saudi Asian Journal of Research in Biological and Pharmaceutical Sciences 2017;5:16-24.

19. Greenwell P. Blood group antigens: molecules seeking a function? Glycoconj J 1997;14:159-73. [CrossRef]

20. El-Sayed MIK, Amin HK. ABO blood groups in correlation with hyperlipidemia, diabetes mellitus type II, and essential hypertension. Asian J Pharm Clin Res 2015;8:236-43.

21. Anvari M, Boroumand M, Emami B, Karimi A, Soleymanzadeh $M$, Abbasi $S$, et al. ABO blood group and coronary artery diseases in Iranian patients awaiting coronary artery bypass graft surgery: A review of 10,641 cases. Labmedicine 2009;40:52830. [CrossRef]

22. Liumbruno GM, Franchini M. Beyond immunohaematology: the role of the $A B O$ blood group in human diseases. Blood Transfus 2013;11:491-9.

23. Ba DM, Sow MS, Diack A, Dia K, Mboup MC, Fall PD, et al. Cardiovascular disease and $A B O$ blood-groups in Africans. Are blood-group $A$ individuals at higher risk of ischemic disease?: A pilot study. Egypt Heart J 2017;69:229-34. [CrossRef]

24. Petrochko $C$. Type O blood carries lower $\mathrm{CHD}$ risk-patients with type $A, B$, or $A B$ blood are at significantly greater risk for coronary heart disease than those with type $O$ blood, researchers found. Cardiology [Online]; 2012. Available at: http://www. medpagetoday.com/ cardiology/myocardialinfarction/34205. Accessed Dec 20, 2018.

25. Spiezia L, Campello E, Bon M, Tison T, Milan M, Simioni P, et al. $A B O$ blood groups and the risk of venous thrombosis in patients with inherited thrombophilia. Blood Transfus 2013;11:250-3.

26. Takagi H, Umemoto T; All-Literature Investigation of Cardiovascular Evidence (ALICE) Group. Meta-Analysis of Non-O Blood Group as an Independent Risk Factor for Coronary Artery Disease. Am J Cardiol 2015;116:699-704. [CrossRef]

27. Nafakhi H, Al-Nafakh H, Al-Mosawi A. ABO blood group differences relationship with coronary atherosclerotic markers. Artery Research 2016;14:36-40. [CrossRef] 
28. Jukic I, Bingulac-Popovic J, Dogic V, Hecimovic A, Babic I, Batarilo $\mathrm{l}$, et al. Evaluation of $\mathrm{ABO}$ blood groups as a risk factor for myocardial infarction. Blood Transfus 2013;11:464-5.

29. Anstee DJ. The relationship between blood groups and disease. Blood 2010;115:4635-43. [CrossRef]

30. Martins J, Olorunju SA, Murray LM, Pillay TS. Comparison of equations for the calculation of LDL-cholesterol in hospitalized patients. Clin Chim Acta 2015;444:137-42. [CrossRef]
31. Onyenekwu CP, Hoffmann M, Smit F, Matsha TE, Erasmus RT. Comparison of LDL-cholesterol estimate using the Friedewald formula and the newly proposed de Cordova formula with a directly measured LDL-cholesterol in a healthy South African population. Ann Clin Biochem 2014;51:672-9. [CrossRef]

32. Fan J, Li N, Gong X, He L. Serum 25-hydroxyvitamin D, bone turnover markers and bone mineral density in postmenopausal women with hip fractures. Clin Chim Acta 2018;477:135-40. 